\section{Karyomapping in Preimplantation Genetic Testing of Patients with Beta-thalassemia and Sickle Cell Anemia}

\author{
Akdeniz Anemili ve Orak Hücreli Anemili Hastaların \\ Preimplantasyon Genetik Testinde Karyomapping \\ Tekniği
}

\begin{abstract}
Aim: This study aimed to first validate the karyomapping technique by using previously known beta globin (HBB) sample test results and then establish it as a sole PGT method for future detection of HBB mutations.

Materials and Methods: The karyomapping protocol was first validated on a total of 30 samples with HBB mutation detected by conventional PGT techniques. Then karyomapping was used in 31 embryo samples as the sole technique to identify the HBB mutation status.

Results: A high concordance (97\%) was found between the karyomapping and conventional PGT results. Five PGT cycles with direct karyomapping for HBB mutations were carried out, and two pregnancies were established by transferring four unaffected and chromosomal normal embryos in two patients.

Discussion and Conclusion: Karyomapping technique can reliably detect HBB mutations during clinical practice without prior test development and prevent the transfer of aneuploid embryos.
\end{abstract}

Keywords: beta globin gene; karyomapping; PGT

Öz

Amaç: Bu çalışmada, karyomapping tekniğini önceden bilinen beta globin (HBB) numunesi test sonuçları üzerinden doğrulamak ve gelecekte HBB mutasyonlarını saptamada kullanılacak tek bir PGT yöntemi olarak ortaya koymak amaçlanmıştır.

Gereç ve Yöntemler: Illk olarak karyomapping protokolü konvansiyonel PGT teknikleri ile saptanmış HBB mutasyonlu toplam 30 örnek üzerinden doğrulandı. Daha sonra 31 embriyo örneğinde HBB mutasyon durumunu tanımlamak için tek teknik olarak karyomapping kullanıldı.

Bulgular: Karyomapping ve konvansiyonel PGT sonuçları arasında yüksek bir uyum (\%97) bulundu. HBB mutasyonları için direkt karyomapping ile beş PGT döngüsü yapıldı ve iki hastaya dört etkilenmemiş ve kromozomal normal embriyo transfer edilerek iki hamilelik elde edildi.

Tartışma ve Sonuç: Karyomapping tekniği klinik uygulamada HBB mutasyonlarını güvenilir bir şekilde saptayabilir ve anöploit embriyoların transferini önleyebilir.

Anahtar Sözcükler: beta globin geni; karyomapping; PGT
Serdar Coskun

Alfaisal University, King Faisal Specialist Hospital and Research Center
Received/Gelis : 28.06.2018 Accepted/Kabul: 09.09.2018

DOI: 10.21673/anadoluklin.438117

Corresponding author/Yazışma yazarı Serdar Coskun

P.O. box 3354 MBC 10, Riyadh, 11211 Saudi Arabia

E-mail: serdar@kfshrc.edu.sa 


\section{INTRODUCTION}

Advanced molecular techniques made it possible to remove individual cells from early embryos for preimplantation genetic testing (PGT) in the assisted reproductive technology (ART) practice. The first successful PGT was performed for sex determination in two families who were at risk of transmitting an X-linked disease, adrenoleukodystrophy, and X-linked mental retardation (1). PGT was later applied in single-gene disorders and eventually became applicable to almost all inherited diseases with known molecular genetic diagnosis (2-3). Moreover, additional techniques such as human leukocyte antigen (HLA) testing of embryos (4) and aneuploidies can also be used along with mutation analysis (5).

PGT was originally developed to test the known mutation in a single cell in a single PCR reaction, which indicates the numerous challenges that are rarely faced in routine molecular diagnostic laboratories due to the limited amount of DNA in embryonic cells (6). These challenges include amplification failure (AF), allele dropout (ADO), and extraneous DNA contamination (7). Accordingly, multiplex PCR was later introduced to co-amplify the several informative linked markers located very close to the disease-causing gene, along with direct mutation testing to improve the diagnostic accuracy (8). Allele-specific PCR enabled the identification of $\mathrm{AF}, \mathrm{ADO}$, or the presence and source of any DNA contamination. However, it requires a long patient- and mutation-specific validation process, and no further testing would be possible in case of any problem with the biopsied sample. To overcome these limitations, whole genome amplification (WGA) techniques are applied, which allow for multiple testing on a single cell with the excess amount of amplified DNA for further analysis (9-10). WGA became a technique preferred over the direct single-cell PCR, and the availability of excessive amount of amplified DNA following WGA allowed for the application of advanced molecular techniques in PGT, including next-generation sequencing and microarray analyses (3).

Karyomapping, a universal linkage-based test, has recently been introduced (11). It utilizes single nucleotide polymorphism (SNP) genotyping of the parents along with a reference of known disease status of a family member to identify the parental origin of chromosomes and disease status of the embryos (12). Karyomapping not only determines the disease status of the embryos, but also provides information about chromosomal abnormalities (13). Its main benefit over the direct mutation tests is its applicability to single or multiple regions covered by informative SNP loci with no need for patient- or disease-specific test development from a single experiment (14). Several live births have been reported in cases of PGT following karyomapping used as a diagnostic test (15-16).

Beta-thalassemia and sickle cell anemia (SCA) are autosomal recessive inherited blood disorders with reduction or absence of the beta globin (HBB) protein (17-18). Phenotypes range from severe anemia to clinically asymptomatic individuals (19). It is common among people of Mediterranean origin, Arabs, and Asians (19-20). PGT is one of the most effective options in the prevention of genetic disease transmission and is widely used in patients with $\mathrm{HBB}$ mutations. About $15 \%$ of the PGT use for single-gene disorders were related to HBB mutations in the ESHRE PGT Consortium data collection (21). Moreover, additional HLA typing along with disease testing makes PGT very attractive for these patients. Although SCA is caused by a single mutation, beta-thalassemia can result from hundreds of different mutations, requiring extensive validation for each mutation and patient (19). Therefore, karyomapping is a promising alternative to the traditional PGT testing.

In our study, we first validated karyomapping on a total of 30 samples with HBB mutation detected by conventional PGT techniques, and then used it directly as a sole method of PGT in patients with HBB mutations.

\section{MATERIALS AND METHODS Retrospective validation}

Four patients underwent PGT for HBB mutations. The diagnosis was made by sequencing and linkage analysis following WGA by multiple displacement amplification (MDA) using biopsied cells from each embryo on day 3. All patients were chosen from women who got pregnant and delivered healthy babies. Following the delivery, a blind KM was performed using the remaining MDA products. Haploblock charts of each embryo from the MDA products were constructed to 


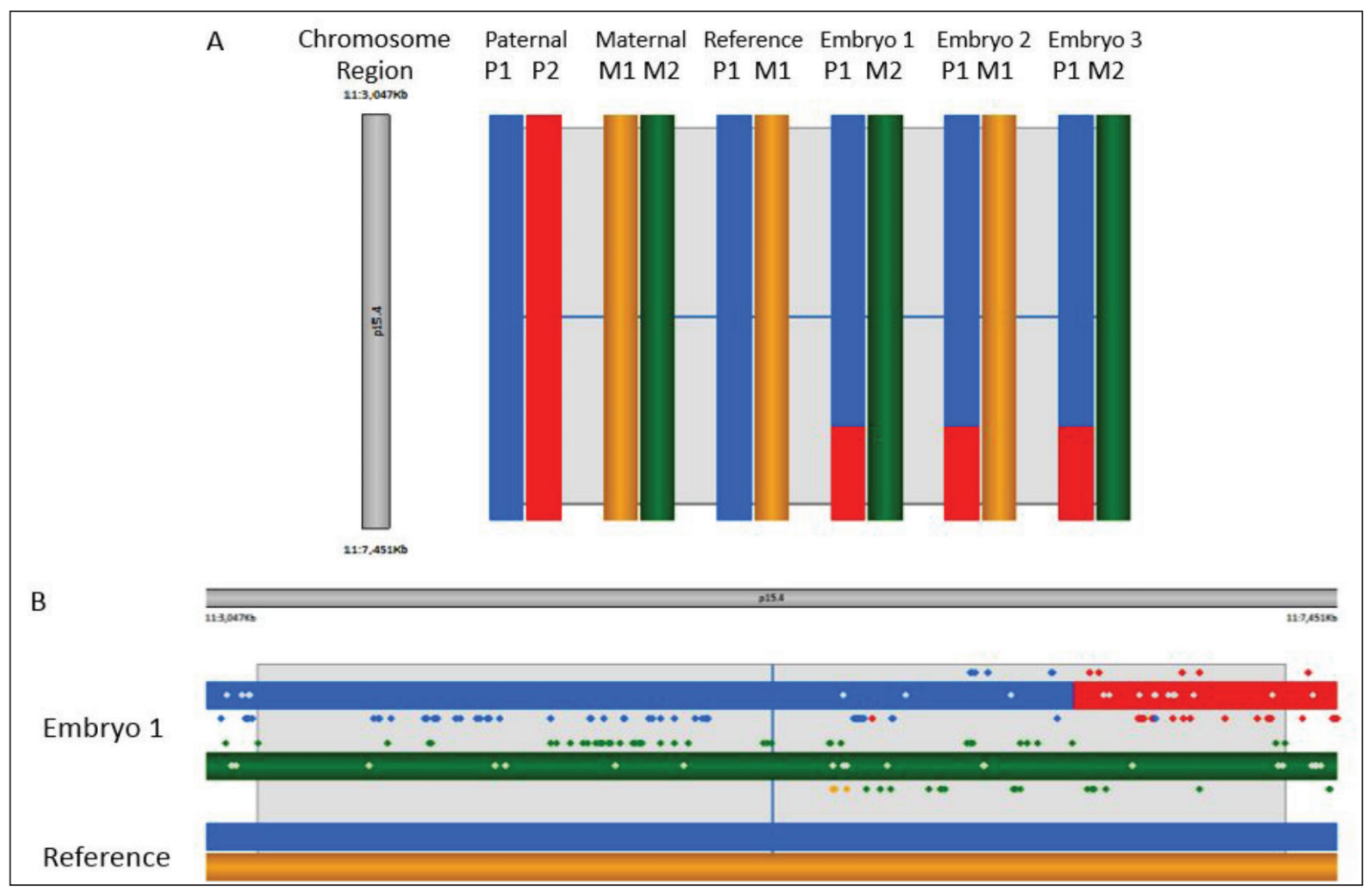

Figure 1. (A) Karyomaps of single blastomeres biopsied from cleavage-stage embryos. Paternal haplotypes are represented in blue(P1)/ $\operatorname{red}(\mathrm{P} 2)$, maternal haplotypes in orange(M1)/green(M2). Haplotypes inherited by the affected reference are shown in blue/orange. Embryo 1 and 3 are carriers of affected paternal and normal maternal allele. Embryo 2 is affected having the same haploblock as the affected reference child. There are crossovers in P1 in all embryos indicating crossovers in the reference. (B) Detailed karyomap of the $\beta$-globin locus (HBB) in Embryo 1. The 2-Mb flanking regions proximal and distal to HBB gene are shown in the gray-shaded box. Key SNPs (upper dots) and nonkey SNPs (lower dots) are used to phase the embryo to the reference. (SNP: single-nucleotide polymorphism.)

predict the presence of any $\mathrm{HBB}$ mutations. Results were compared to the sequencing and linkage analysis of the original cycles. The study was conducted in accordance with the Declaration of Helsinki principles.

\section{PGT cycles with karyomapping}

A total of five patients with different HBB mutations were included. Of the couples, two were carriers of beta-thalassemia and three carriers of SCA. In addition, two couples, one with beta-thalassemia and one with SCA, were also carriers of glucose-6-phosphate dehydrogenase (G6PD) deficiency (Table 1). One of the beta-thalassemia couples also asked for HLA typing for their embryos to be a stem cell donor for an affected sibling. For these cycles, embryo biopsy was again performed on day 3 and karyomapping was used as the sole diagnostic procedure.

\section{Cycles}

Ovarian stimulation, oocyte retrieval, intracytoplasmic sperm injection (ICSI) procedure, embryo biopsy, cell lysis, and MDA were performed as previously described $(9,22)$. For WGA, multiple displacement amplification was utilized according to the manufacturer's instructions for cell lysing, neutralization, and amplification steps of REPLI-g midi kit (Qiagen). Negative and positive controls were included in each PGD. Following WGA, mutation detection results were compared to DNA sequencing and linkage by a short tandem repeat (STR) identifier analysis of the original cycle of the validation cycles. The remaining MDA products from these cycles were used to validate the karyomapping analysis. For PGT cycles with direct karyomapping, MDA products were used directly.

\section{Karyomapping}

Karyomapping was performed as previously described (12). Briefly, all DNA samples were quantified, and SNP genotyping was carried out using Illumina Human CytoSNP-12 bead arrays. Processed arrays were scanned, and the image data were analyzed and 


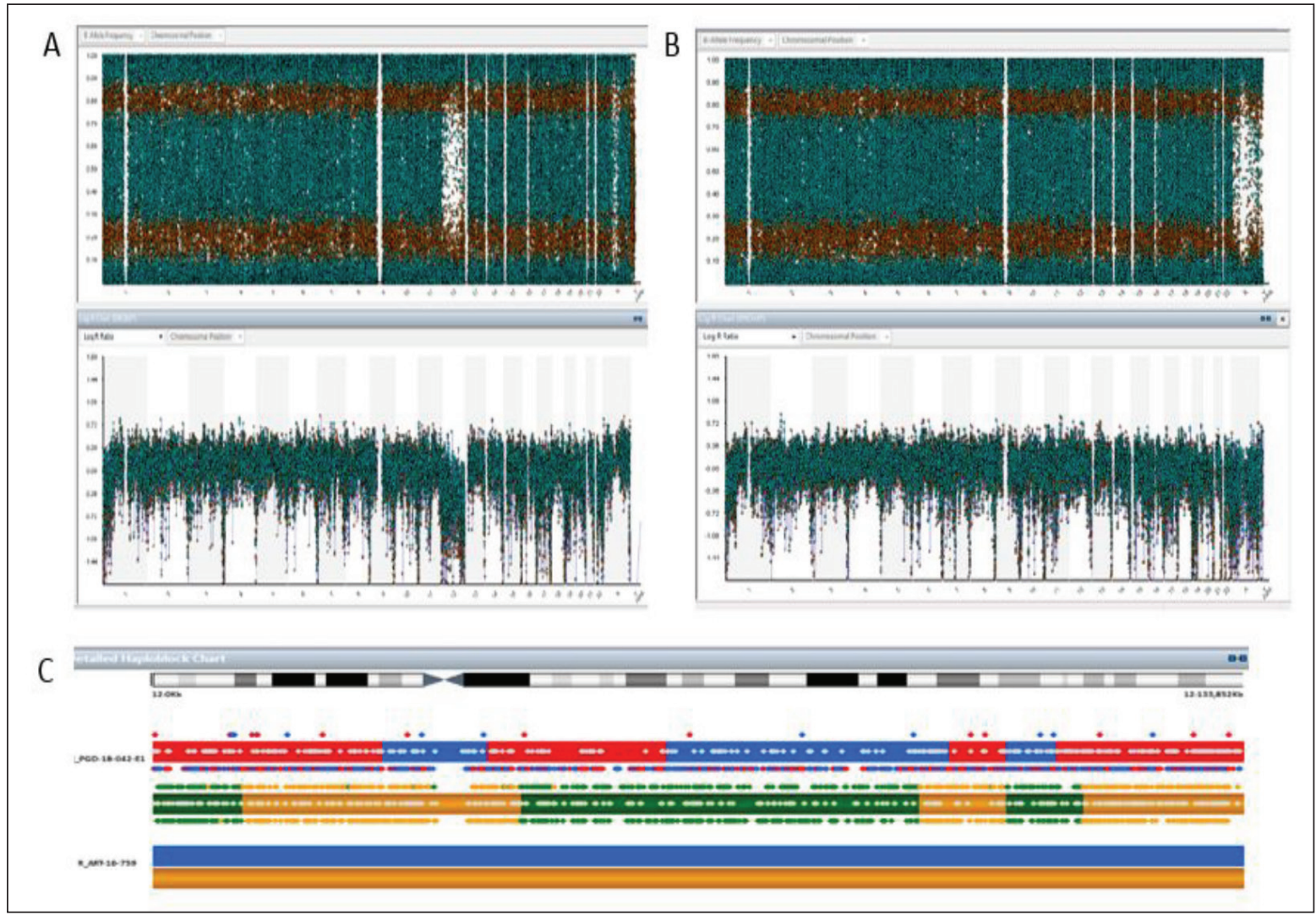

Figure 2. Examples of chromosomal analysis by karyomapping. (A) Abnormal chromosome pattern (monosomy 12), evident in a significant shift in $\log$ R ratio and B-allele frequency; (B) Normal chromosomal pattern with the presence of one $\mathrm{X}$ and one $\mathrm{Y}$ chromosome; (C) detailed haploblock analysis of chromosome 12 indicated the loss of paternal contribution, evident with mixed blue and red non-key SNPs.

converted to genotype data for karyomap analysis. The parental genotype combinations at each SNP locus were analyzed to identify the informative loci in which one parent is homozygous and the other heterozygous and the genotype of one of the siblings is selected as the reference (Figure 1). Beta allele charts were used to detect chromosomal abnormalities (Figure 2).

\section{RESULTS}

\section{Retrospective validation}

Whole genome-amplified DNA from 30 embryos biopsied on day 3 from earlier PGT cycles was used for DNA sequencing and linkage analysis. In these samples, karyomapping was performed retrospectively on the leftover MDA products. Out of the 30 embryos, only one MDA product failed to give a successful result due to low call rates. The remaining 29 embryos had valid call rates for the diagnosis. The average call rates and $\mathrm{AB}$ call rates for DNA were 96 and 30\%, and for the MDA products 72 and 15\%, respectively. Of these, 23 samples had the same diagnosis in all three techniques (DNA sequencing, linkage analysis, and karyomapping). In five embryos, DNA sequencing results differed from those of the other two techniques, probably due to ADO during the sequencing process (Figure 3). One embryo was identified as affected by sequencing and linkage analysis, and gave a chaotic chromosomal analysis by karyomapping. It did not have any paternal contribution with six missing maternal chromosomes. The overall agreement with conventional PGT results compared to karyomapping was $97 \%$.

\section{PGT cycles with karyomapping}

A total of 53 oocytes were obtained from the five patients, and 41 matured oocytes were injected with a single spermatozoon of the husband. Of the 41 injected oocytes, 32 (80\%) were fertilized and 31 were biopsied on day 3. Karyomapping analysis was possible in all embryos. In two cases, karyomapping analysis was 


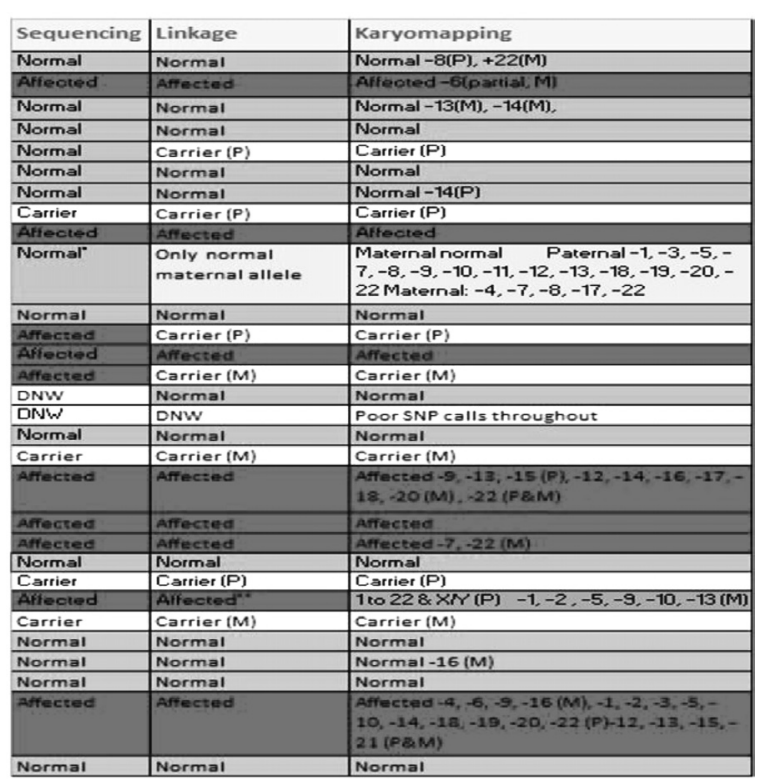

Figure 3. Comparison of PGT testing by different methods during validation. (P: paternal; M: maternal; DNW: did not work.)

* Normal by sequencing and only maternal allele was present by PGH and KM (monosomy).

** HBB region was homozygous in the affected child and linkage analysis. Absence of the paternal haplotype did not allow to predict the haplomap of the embryo.

performed for two loci, HBB at chromosome 11p15.4 and X-linked G6PD loci at Xq28 region. Out of 22 embryos, 12 were unaffected for both regions, with the status normal/normal, normal/carrier, or carrier/ carrier (Table 3). However, 50\% of these unaffected embryos were chromosomally abnormal. One of the patients tested for both HBB and G6PD genes had an embryo transfer and a successful twin pregnancy was established. The other patient did not have embryo transfer since the only embryo with unaffected karyomap and normal chromosomal constituent had an embryonic developmental arrest by day 5 . The other three patients who harbored only HBB mutations had four carrier and five affected embryos. Of the four carrier embryos, two were from a patient who had normal chromosomal constituents. These embryos were transferred and another twin pregnancy was established. Unfortunately, two of the patients did not have any unaffected/euploid embryos to transfer. Additionally, for a couple who requested HLA typing, though not having any transferable embryos, HLA karyomapping was performed for extra information with no fully matched embryos available (Figure 4).

\section{DISCUSSION AND CONCLUSION}

In this study, we successfully validated karyomapping as a technique to detect $\mathrm{HBB}$ mutations in patients with SCA and beta-thalassemia. In addition, G6PD and HLA loci were also analyzed along with HBB loci without any additional experimentation. The conventional PGT testing relies on the sequencing of the region of interest along with linkage analysis of up- and down-stream of that region to increase the diagnostic accuracy (22). This requires patient- and mutationspecific pre-PGT workup, which necessitates a long optimization procedure (13). When there is a second mutation or a need for HLA typing, such optimization becomes even more difficult and time consuming (14). Karyomapping requires only the identification of the informative SNPs before starting the cycle, which can be accomplished by a single run within a week. If other loci should be included and tested, there is no need for additional experimentation (12). A second karyomap analysis with the same experimental data can be performed in a very short time. However, a prerequisite of karyomapping is the availability of a family member with known disease status with a sufficient number of key informative SNPs in the region of interest (12). Furthermore, karyomapping allows for analyzing chromosomal aneuploidies along with gene-specific linkage analysis (13).

The validation of karyomapping was performed by using the archived MDA samples from the previous cycles where conventional PGT testing was performed for HBB mutations. Overall concordance of sequencing, linkage analysis, and karyomapping was 79.3\% $(23 / 29)$. Of the remaining six embryos, five were concordant between karyomapping and linkage analysis. Four embryos were carriers by both linkage analysis and karyomapping. However, sequencing analysis showed that there were two normal, two affected, and one with AF. It is well-known that ADO is common during PGT and it might reach $>20 \%$ (6). Therefore, including linkage analysis or performing karyomapping mostly eliminate misdiagnosis during PGT testing due to $\mathrm{ADO}$ or AF. Otherwise, two carrier embryos would have been discarded as affected. Moreover, two carrier embryos would have been transferred as normal. The concordance of linkage analysis and 


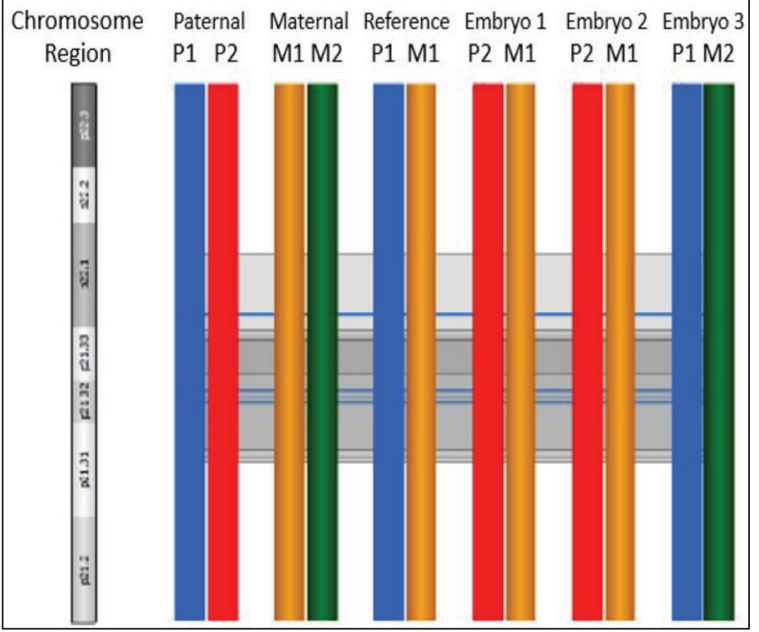

Figure 4. HLA typing of single blastomeres biopsied on day 3. Paternal HLA haplotypes are represented in blue(P1)/red(P2), maternal HLA haplotypes in orange(M1)/green(M2). Haplotypes inherited by the affected reference are shown in blue/orange. None of the embryos matched the reference child in need of HLA-matched bone marrow transplantation.

karyomapping was $96.6 \%$ (28/29), which was close to the $97 \%$ reported by Natesan et al. (12).

One embryo was concordant between the sequencing and linkage analysis that showed affected homozygous pattern. Karyomapping did not reveal the phase of the embryo. However, the comprehensive chromosomal analysis confirmed the embryo as monoploid since it did not have any of the paternal SNPs. A similar pattern of such paternal monosomy has also been recently reported in the diagnosis of Marfan syndrome along with cytogenetic analysis by karyomapping (13). They speculated that it could be due to parthenogenetic activation undetectable by aCGH (13). This embryo was discarded since it was abnormal. However, in case of carrying normal maternal chromosome by sequencing and linkage analysis while being monoploid, it could have been transferred without karyomapping analysis. Therefore, karyomapping prevents the transfer of embryos that have no chance of implantation or resulting in miscarriage/ babies with chromosomal abnormalities. However, it should also be kept in mind that karyomapping cannot diagnose mitotic trisomies (23).

Upon successful validation, karyomapping was used as the sole technique of PGT in the second part of the study. A total of five couples were included and all 31 embryos had full diagnosis. Two couples were carriers of both HBB and G6PD mutations. Karyomapping allowed for diagnosis through a single experiment by analyzing both loci separately. The conventional method for two loci PGT requires a long optimization and validation process prior to initiating the cycle (14). Karyomapping can be directly used regardless of mutation type or locus number in the same experiment including HLA typing (11).

There were a total of 16 transferable embryos diagnosed as normal or carrier genotype. Further analysis of chromosomal status excluded eight (50\%) embryos due to aneuploidy, which agrees with the published results of embryonic aneuploidies (24). A good correlation between the aneuploidy results of aCGH and karyomapping has been reported $(23,25)$. The inclusion of chromosomal analysis with karyomapping also prevented transfer of the aneuploid normal/carrier embryos in two couples. Although cancelling embryo transfer is upsetting to the patients, it prevented unnecessary treatment for luteal phase support until the negative pregnancy test. In case of positive pregnancy, it could end up with miscarriage or an abnor-

\begin{tabular}{llllll}
\hline \multicolumn{2}{l}{ Patient Age } & Disease 1 & Mutation 1 & Disease 2 & Mutation 2 \\
\hline $\mathbf{1}$ & 31 & Beta thalassemia & IVS II-1 G>A & G6PD deficiency & S188F \\
$\mathbf{2}$ & 35 & Beta thalassemia & IVS I3' (-25bp dell) & NA & \\
$\mathbf{3}$ & 32 & Sickle cell & p.E6V & G6PD deficiency & S188F \\
$\mathbf{4}$ & 32 & Sickle cell & p.E6V & NA & \\
$\mathbf{5}$ & 43 & Sickle cell & p.E6V & NA & \\
\hline
\end{tabular}

Table 1. Patient age and diseases and the associated mutations in cycles with direct karyomapping. (G6PD: glucose-6-phosphate dehydrogenase; NA: not applicable.)

\begin{tabular}{|c|c|c|c|c|c|c|c|c|c|c|c|}
\hline$\#$ & Testing & Biopsied & N A & C & $\mathrm{N} / \mathrm{C}$ & N/A & $\mathbf{C} / \mathbf{A}$ & $\begin{array}{c}\text { HLA } \\
\text { matched }\end{array}$ & Euploid* & ET & $\begin{array}{c}\text { Gestational } \\
\text { sac }\end{array}$ \\
\hline 1 & HBB+G6PD & 17 & 30 & 4 & 3 & 4 & 3 & & $5 / 10$ & 2 & 2 \\
\hline 2 & $\mathrm{HBB}+\mathrm{G} 6 \mathrm{PD}$ & $5^{\#}$ & 10 & 0 & 1 & 1 & 0 & & $1 / 2$ & 0 & 0 \\
\hline 3 & $\mathrm{HBB}+\mathrm{HLA}$ & 3 & 01 & 2 & & & & 0 & $0 / 2$ & 0 & 0 \\
\hline 4 & HBB & 5 & 03 & 2 & & & & & $2 / 2$ & 2 & 2 \\
\hline 5 & HBB & 1 & 01 & 0 & & & & & 0 & 0 & 0 \\
\hline & Total & 31 & 45 & 8 & 4 & 5 & 3 & & $8 / 16$ & 4 & 4 \\
\hline
\end{tabular}

Table 2. Karyomapping results with cycle outcomes. NA results are shaded.

* Out of the transferable embryos.

** Two embryos did not have enough SNP coverage in the HBB region to phase the embryo. Since they were chromosomally abnormal, no further analysis was carried out. 
mal child of much greater psychological and financial effect. Karyomapping prevented such undesirable consequences. Although the number is low to suggest with certainty, high implantation and pregnancy rates could be obtained following karyomapping, as also reported by Konstantinidis et al. (15).

In conclusion, karyomapping can be reliably used as a sole PGT technique to detect HBB mutations without prior test development, regardless of mutation type. Moreover, additional loci were analyzed without additional experimentation. Since karyomapping provides information about chromosomal abnormalities, it prevents the transfer of aneuploid embryos.

\section{REFERENCES}

1. Handyside AH, Kontogianni EH, Hardy K, Winston RM. Pregnancies from biopsied human preimplantation embryos sexed by Y-specific DNA amplification. Nature. 1990;344(6268):768-70.

2. Handyside AH, Lesko JG, Tarin JJ. Birth of a normal girl after in vitro fertilization and preimplantation diagnostic testing for cystic fibrosis. N Engl J Med. 1992;327(13):905-9.

3. Sermon K. Novel technologies emerging for preimplantation genetic diagnosis and preimplantation genetic testing for aneuploidy. Expert Rev Mol Diagn. 2017;17(1):71-82.

4. Verlinsky Y, Rechitsky S, Schoolcraft W, Strom C, Kuliev A. Preimplantation diagnosis for Fanconi anemia combined with HLA matching. JAMA. 2001;285(24):31303.

5. Hellani A, Coskun S, Benkhalifa M. Multiple displacement amplification on single cell and possible PGD applications. Mol Hum Reprod. 2004;10(11):847-52.

6. Coskun S, Alsmadi O. Whole genome amplification from a single cell: a new era for preimplantation genetic diagnosis. Prenat Diagn. 2007;27(4):297-302.

7. Findlay I, Ray P, Quirke P, Rutherford A, Lilford R. Allelic drop-out and preferential amplification in single cells and human blastomeres: implications for preimplantation diagnosis of sex and cystic fibrosis. Hum Reprod. 1995;10(6):1609-18.

8. Findlay I, Matthews PL, Mulcahy BK, Mitchelson K. Using MF-PCR to diagnose multiple defects from single cells: implications for PGD. Mol Cell Endocrinol. 2001;183(Suppl 1):S5-12.

9. Hellani A, Coskun S, Tbakhi A, Al-Hassan S. Clinical application of multiple displacement amplification in preimplantation genetic diagnosis. Reprod Biomed Online. 2005;10(3):376-80.

10. Handyside AH, Robinson MD, Simpson RJ, Omar MB, Shaw MA, Grudzinskas JG, et al. Isothermal whole genome amplification from single and small numbers of cells: a new era for preimplantation genetic diagnosis of inherited disease. Mol Hum Reprod. 2004;10(10):767-72.

11. Handyside AH, Harton GL, Mariani B, Thornhill AR, Affara N, Shaw MA, et al. Karyomapping: a universal method for genome wide analysis of genetic disease based on mapping crossovers between parental haplotypes. J Med Genet. 2010;47(10):651-8.

12. Natesan SA, Bladon AJ, Coskun S, Qubbaj W, Prates $\mathrm{R}$, Munne $\mathrm{S}$, et al. Genome-wide karyomapping accurately identifies the inheritance of single-gene defects in human preimplantation embryos in vitro. Genet Med. 2014;16(11):838-45.

13. Thornhill AR, Handyside AH, Ottolini C, Natesan SA, Taylor J, Sage K, et al. Karyomapping-a comprehensive means of simultaneous monogenic and cytogenetic PGD: comparison with standard approaches in real time for Marfan syndrome. J Assist Reprod Genet. 2015;32(3):347-56.

14. Gould RL, Griffin DK. Karyomapping and how is it improving preimplantation genetics? Expert Rev Mol Diagn. 2017;17(6):611-21.

15. Konstantinidis M, Prates R, Goodall NN, Fischer J, Tecson V, Lemma T, et al. Live births following karyomapping of human blastocysts: experience from clinical application of the method. Reprod Biomed Online. 2015;31(3):394-403.

16. Ben-Nagi J, Wells D, Doye K, Loutradi K, Exeter H, Drew E, et al. Karyomapping: a single centre's experience from application of methodology to ongoing pregnancy and live-birth rates. Reprod Biomed Online. 2017;35(3):264-71.

17. Ottolenghi S, Lanyon WG, Williamson R, Weatherall DJ, Clegg JB, Pitcher CS. Human globin gene analysis for a patient with beta-o/delta beta-thalassemia. Proc Natl Acad Sci U S A. 1975;72(6):2294-9.

18. Saiki RK, Chang CA, Levenson CH, Warren TC, Boehm CD, Kazazian HH Jr., et al. Diagnosis of sickle cell anemia and beta-thalassemia with enzymatically amplified DNA and nonradioactive allele-specific oligonucleotide probes. N Engl J Med. 1988;319(9):537-41.

19. Weatherall D, Clegg JB. Inherited haemoglobin disorders: an increasing global health problem. Bull World Health Organ. 2001;79(8):704-12. 
20. Teo CG, Wong HB. The innate resistance of thalassemia to malaria: a review of the evidence and possible mechanisms. Singapore Med J. 1985;26:504-9.

21. Goossens V, Traeger-Synodinos J, Coonen E, De Rycke M, Moutou C, Pehlivan T, et al. ESHRE PGD Consortium data collection XI: cycles from January to December 2008 with pregnancy follow-up to October 2009. Hum Reprod. 2012;27(7):1887-911.

22. Coskun S, Hollanders J, Al-Hassan S, Al-Sufyan H, Al-Mayman H, Jaroudi K. Day 5 versus day 3 embryo transfer: a controlled randomized trial. Hum Reprod. 2000;15(9):1947-52.

22. Qubbaj W, Al-Swaid A, Al-Hassan S, Awartani K, Deek H, Coskun S. First successful application of preimplantation genetic diagnosis and haplotyping for congenital hyperinsulinism. Reprod Biomed Online. 2011;22(1):72-9.
23. Natesan SA, Handyside AH, Thornhill AR, Ottolini CS, Sage K, Summers MC, et al. Live birth after PGD with confirmation by a comprehensive approach (karyomapping) for simultaneous detection of monogenic and chromosomal disorders. Reprod Biomed Online. 2014;29(5):600-5.

24. Simon AL, Kiehl M, Fischer E, Proctor JG, Bush MR, Givens C, et al. Pregnancy outcomes from more than 1,800 in vitro fertilization cycles with the use of 24-chromosome single-nucleotide polymorphism-based preimplantation genetic testing for aneuploidy. Fertil Steril. 2018;110(1):113-21.

25. Giménez C, Sarasa J, Arjona C, Vilamajó E, MartínezPasarell O, Wheeler K, et al. Karyomapping allows preimplantation genetic diagnosis of a de-novo deletion undetectable using conventional PGD technology. Reprod Biomed Online. 2015;31(6):770-5. 